\title{
INFLUENCE OF PSYCHOLOGICAL CHARACTERISTICS ON THE EFFICIENCY OF THE PERFORMANCE OF THE DEFENCE AGAINST ATTACKS BY THE HAND
}

\author{
Drako Paspalj ${ }^{1}$ \\ ${ }^{1}$ Internal Affairs College, Banja Luka, Bosnia and Herzegovina
}

\begin{abstract}
SUMMARY
Based on the fact that psychological characteristics play a significant role in the training of special physical education, both for programming of selection diagnostics and programming methods and means to overcome specific curriculum, a study conducted aimed to determine the effect of cognitive and conative characteristics of students of the Internal Affairs College on the quality of the performance of the defense against attacks by the hand to the head from the special physical education program. The study was conducted on 70 students of both sexes of the third year of the internal Affairs College in Banja Luka, aged between 21 and 23 years. Regression analysis showed a significant effect of joint variables for assessing cognitive and conative characteristics on the performance of the defense against attacks by the hand to the head where the single statistically significant effect in explaining criterion has been achieved by: test of visual specializing (S1) designed for simultaneous assessment of education of spatial relations, test of anxiety (alpha) was used to estimate the efficiency of the defense regulation and control system and test of social disintegratedness (ETA) that was used to estimate the efficiency of the integration of regulatory functions, based on which we can assume that these variables are predictive for the successful execution of the defense against attacks by the hand to the head from the special physical education program and should be taken into consideration in the planning and realization of the process in solving situational-motor problems in familiar and unfamiliar conditions.
\end{abstract}

Key Words: attack by hand, defense, psychological characteristics.

\section{INTRODUCTION}

Bearing in mind the fact that man as a system occupies a central place in achieving the objectives of the Special physical education, in order to meaningfully could influence its development is necessary to know its structure, its way of functioning and adaptive characteristics. Special Physical Education (hereafter SPE), as one of the narrow professional subjects of the Internal Affairs College, has the task to, using a variety of activities, form a proper system of response and to enable the students to perform well in addition to other activities that require the use of force in resolving problem situations with different levels of complexity. Already because of the fact that the performance of professional duties and obligations implies the use of firearms, it is necessary that the students of the Internal Affairs College master specific skills that will enable them to more effectively carry out their activities. The current model of education in the SPE, which is conducted at the Internal Affairs College in Banja Luka phase involves learning specific and very complex motor structures and their application in a variety of determinants and functions of the goal. Learning takes place through elementary, vocational and situational training, each phase has its own goals and tasks to be accomplished through certain processes trough which they learn new motor skills, develop the right motor programs and develop adaptive characteristics. Because police officers are often the target of physical attack by one or more persons, special attention is paid to training the successful execution of the defense and the establishment of full control over the attackers. Given 
the fact that defense programming is a complex cognitive activity that involves observing and understanding spatio-temporal relations as a whole, identifying and recognizing your opponent's actions, comparing the recognized motor program with a program that needs to be realized, the selection of appropriate software, select and add appropriate values for the selected program and giving orders to implement, while impact of these activities in real work situations can be summarized in a binary variable success - failure with the aim of control or destruction of the opponent, it is assumed that cognitive abilities and conative characteristics play an important role in its implementation. Cognitive abilities have influence on the formation of programs that operate control mechanisms for programming and reprogramming of motor algorithms responsible for timely, accurate and rapid means of force application (techniques to bring, defend against unarmed and armed attackers, the use of firearms and other means of force), whereby the effective functioning of the particular process can be estimated by timely and appropriate decision-making on the activities in conditions where the means of force can be applied (it comes to the close cooperation of the highest levels of the central nervous system, responsible for receiving and processing information and making decisions on actions). Considering that the means of force are applied in terms of attack rejection, overcoming resistance or escape, put very high demands in front of a police officer: to estimate the fraction of a second all the circumstances, make the right decision and to apply adequate means of force, aware of the consequences that the use of the means of force may result on the person but also the consequences that would follow the service and specific duty of the police officer if he refrained from applying adequate means of force. Tactics in use of force resources require a trained, qualified and physically ready professional who clearly knows the rules and has the ability to quickly recognize the specific situation, make a proper evaluation and effectively use means of force in the permitted way. In order for the decision making to be qualitative, we need recognize the need for making decisions and be aware that there are time limits for it, which is determined by the problem situation and the intention of gaining an advantage over a rival. Before making a decision on the action it is necessary to analyze the information caused by people that prevent individual performances (age, sex, number of people, their skills), spatial and time factors, then their knowledge and skills and the fulfillment of legal conditions for the application of individual means of force, and based on their efficiency criteria to make a decision on taking appropriate action. For this reason it is necessary to train the students of the Internal Affairs College for the use of physical force (as an appropriate and adequate mean of the force), in order for this application to be lawful, proper, impartial, effective and restrictive, and that with the least harmful effects provide services and tasks within the police jurisdiction. According to Milošević, Mudrić, Jovanović, Amanović, \& Dopsaj (2005), cognitive skills are important for the effective application of techniques from the program of SPE in combat, because police officers need to recognize the actions of the opponents, to distinguish the important from the less important elements of movement for certain situations, predict motion changes and to solve various problems in which the spatial relationships are portrayed visually. Also, they have to qualitative and quick establish interrelations between elements of the current situation and to properly and quickly select the tactic of treatment whereby a high working level of processes responsible for the analysis, programming and data storage, provides a high level of efficiency using various techniques of defense and attack. Given the fact that in the training, there are no existing programs for dealing with situational conditions, cognitive processes are current in the analysis of a case problem and the formation of motor responses, and conative characteristics whether acting directly or complement each other, form a synergy or make certain disorders in the task performance, causing such behaviours that promote or prevent certain processes in order to establish control over the movement effects. Knowledge of the hierarchical structure of psychological attributes and characteristics allows the teacher to understanding and predicting the behaviour of students in problem-solving situations with different levels of complexity. Starting from the assumption that psychological characteristics have a certain role in the training of special physical education, and that in the previous period through a series of studies was confirmed that parts of the personality (cognitive and conative domain) do not operate as separate, isolated units, but are linked together and act in mutual conjunction (Momirović \& Horga, 1990; Stojiliković, 1995; Vučinić, Popović, \& Momirović, 1992), a study conducted that aimed to determine whether, and to what extent the observed psychological characteristics of students of the Internal Affairs College in Banja Luka have an impact on the efficiency of the defense against attacks by the hand to the head. The results of this type of research would be of theore- 
tical and practical value for the teaching of special physical education because they can provide the possibility to choose new teaching methods and resources, introducing in the program structure of subject matter specific problem situations with which police officers most commonly encountered in the field, and whose criterion for resolution is harmonized with the behaviour of persons against whom they need to apply certain means of force.

\section{METHODS}

\section{Sample of subjects}

The study was conducted on 70 students (44 male and 26 female subjects) of the fifth semester of the College of Internal Affairs in Banja Luka, of the 2007/2008 academic year. The sample included students aged between 21 and 23 years.

\section{Sample of variables}

The Sample of variables in this study is divided into predictor variables and the variables of the cri- terion system. Pattern of predictor variables consisted of a set of nine variables for assessing the psychological characteristics of subjects, and 3 variables for the assessment of cognitive abilities and 6 variables for the assessment of cognitive characteristics. Their name, the subject and the measurement reliability of the coefficients are given in Table 1.

The table shows that all the variables for assessing psychological characteristics have the necessary metrical characteristics (Momirović, Wolf, \& Džamonja, 1992). The examination of the psychological characteristics of samples was performed in groups (from 18 to 25 subjects) in specific areas that met the standard requirements for group psychological testing. Psychologist-examiner is fully complied with the procedures related to the implementation of testing (explained research objectives and provide general motivational and instructions), whereby he led a protocol on testing in which he amounted all the information and events that could affect the regularity tests. Trough the insight into these protocols it can be concluded that all the group tests conducted under regular circumstances and that all subjects

TABLE 1

Title, case measurement and reliability of predictor variables.

\begin{tabular}{llc}
\hline \multicolumn{1}{c}{ Title } & \multicolumn{1}{c}{ Case measurement } & Reliability \\
\hline IT1 & The efficiency of perceptual processors & .91 \\
\hline AL4 & The efficiency of serial processors & .94 \\
\hline S1 & The efficiency of parallel processors & .92 \\
\hline EPSILON & Activity regulation & .90 \\
\hline HI & Regulation of organic functions & .89 \\
\hline ALFA & Regulation of defense reactions & .92 \\
\hline SIGMA & Regulation of attack reactions & .90 \\
\hline DELTA & Coordination of regulatory functions & .91 \\
\hline ETA & Integration of regulatory functions & .91 \\
\hline
\end{tabular}

were motivated for the examination. The criterion variable was represented by the score of quality assessment of the performance of the defense against attacks by the hand to the head with a step forward with the same named leg, and has already been formed by performing the average score by five experts who teach the SPE in the a scale of 5.00 to 10.00 . The criterion of evaluation was as follows:

Grade 10 (ten) - uniform and coordinated performance in the optimal rhythm of techniques that satisfy the principles for solving the specific problem situation, the basic principles of biomechanics and provide a safe and complete control of the attacker.

Grade 9 (nine) - excellent performance of techniques, with one of the components being a little disturbed, but the performance is still very safe.
Grade 8 (eight) - good performance of technique, the appearance of small errors, where the basic structure of the elements is not disrupted, and performance is still safe.

Grade 7 (seven) - pretty good performance of technique element, there is a slightly higher number of errors, the basic principles are not significantly disturbed and there is some uncertainty in the performance of his defense.

Grade 6 (six) - the basic structure of the technique is partially disturbed, lack of complete control over the attacker and unsafe design.

Grade 5 (five) - poor performance, larger defects, the structure of movement is substantially impaired, extreme uncertainty. 


\section{Statistical analysis of data}

Data analysis was performed using the software package SPSS 17.0, with descriptive statistical parameters calculated for each variable while for the determination of the impact of the system of predictor variables on the criterion variable we used regression analysis.

\section{RESULTS}

Table 2 shows the descriptive value of the variables in the area of cognitive skills and cognitive performance. It turned out that the majority of the distribution of the results fairly well grouped and that there are no significant deviations from the mean results. Results of the Kolmogorov-Smirnov test showed that most of the variables have a symmetrical distribution. The exceptions are the variables of conversion test (HI) and test of psychotizismus (DELTA), in which the distribution deviates signifi- cantly from the Gaussian curve. The highest range of scores and the maximum deviation from the mean value of results was recorded in variables: test anxiety (alpha), test of aggression (Sigma) and test intro-extroversion (EPSILON). It can be seen that the greater asymmetry Skewness to the right compared to normal distribution shows in variable: test of conversion (HI) test and psychotizismus (DELTA), while other variables recorded small and medium asymmetry in the accordance with the prefix. Assessments of the degree of curvature Kurtosis it was observed that higher values of kurtosis also show variables: test of conversion (HI) test and psychotizismus (DELTA), while other variables do not deviate from the normal distribution.

Table 3 shows the relationship between the dependent variable of the defense against attacks by the hand to the head (DAHTH) and the associated independent variables for assessing cognitive and conative characteristics. The coefficient of multiple correlation $(R=.516)$ indicates a significant approval of the

TABLE 2

Descriptive indicators of psychological characteristics of subjects.

\begin{tabular}{lccccrrrrr}
\hline Variables & $N$ & Min & Max & \multicolumn{1}{c}{$M$} & \multicolumn{1}{c}{$S D$} & Skew. & Kurt. & \multicolumn{1}{c}{ KS } & \multicolumn{1}{c}{$\mathrm{p}$} \\
\hline IT1 & 70 & 15 & 31 & 20.97 & 3.467 & .560 & -.315 & 1.169 & .130 \\
\hline AL4 & 70 & 18 & 40 & 32.63 & 5.525 & -.573 & -.560 & 1.061 & .210 \\
\hline S1 & 70 & 14 & 30 & 23.33 & 4.429 & -.316 & -.973 & .982 & .290 \\
\hline EPSILON & 70 & 78 & 150 & 115.74 & 15.014 & -.180 & .019 & .551 & .922 \\
\hline HI & 70 & 30 & 75 & 39.33 & 8.810 & 1.501 & 2.931 & 1.458 &. $\mathbf{0 2 9}$ \\
\hline ALFA & 70 & 30 & 106 & 60.47 & 18.981 & .378 & -.653 & .846 & .471 \\
\hline SIGMA & 70 & 34 & 109 & 77.26 & 15.048 & -.191 & -.131 & .665 & .769 \\
\hline DELTA & 70 & 30 & 70 & 39.89 & 9.048 & 1.504 & 1.806 & 1.880 & .002 \\
\hline ETA & 70 & 30 & 82 & 47.21 & 12.225 & .708 & -.044 & .895 & .400 \\
\hline
\end{tabular}

Legend: IT1 - The efficiency of perceptual processors; AL4 - The efficiency of serial processors; S1 - The efficiency of parallel processors; EPSILON - Activity regulation; HI - Regulation of organic functions; ALFA - Regulation of defense reactions; SIGMA - Regulation of attack reactions; DELTA - Coordination of regulatory functions; ETA - Integration of regulatory functions; $N$ - Total number of partcipants; Min - Minimum; Max - Maximum; $M$ - Sample mean; $S D$ - Standard deviation; Skew. - Skewnis; Kurt. - Kurtosis; $K-P$ - Konglo-Smirnov tets; $\boldsymbol{p}$ - Probability.

dependent variable with the independent variables. The coefficient of determination $\left(R^{2}=.266\right)$ indicates that $26.6 \%$ of the total variability of the depending variable can be explained by the independent variables associated with the assessment of cognitive and conative characteristics, while the remaining $73.4 \%$ of the variability is influenced by other (unexplained) factors. Based on the value of F-test (2.414) and the achieved level of significance ( $p=.021)$ it can be concluded that on the basis of psychological characteristics may be possible in some degree to predict the efficiency of execution of the defense against attacks by the hand to the head.

Table 4 shows the values of beta coefficients, which provide information on the partial impact of independent variables on the criterion variable. A 


\section{TABLE 3}

Regression analysis of associated predictors and the defense against attacks by the hand to the head.

\begin{tabular}{ccccc}
\hline$R$ & $R^{2}$ & $S D$ & $F$ & $p$ \\
\hline .516 & .266 & .93272 & 2.414 & .021 \\
\hline
\end{tabular}

Legend: $\mathbf{R}$ - Coefficient of multiple correlation; $R^{2}$ - Coefficient of determination; $S D$ - Standard deviation; $F$ - F-test; $p$ - Probability.

\section{TABLE 4}

Regression and associated predictors of the defense against attacks by hand.

\begin{tabular}{lrrrrr}
\hline \multicolumn{1}{r}{ Model } & \multicolumn{1}{c}{$\mathrm{B}$} & \multicolumn{1}{c}{ SE } & $\beta$ & \multicolumn{1}{l}{$t$} & \multicolumn{1}{c}{$p$} \\
\hline (Constant) & 6.188 & 1.614 & & & \\
\hline IT1 & .004 & .035 & .014 & .110 & .913 \\
\hline AL4 & -.010 & .022 & -.056 & -.460 & .647 \\
\hline S1 & .064 & .029 & .281 & 2.231 & .029 \\
\hline EPSILON & -.006 & .009 & -.092 & -.700 & .487 \\
\hline HI & -.015 & .023 & -.133 & -.654 & .515 \\
\hline ALFA & .034 & .010 & .635 & 3.374 & .001 \\
\hline SIGMA & .014 & .009 & .203 & 1.541 & .128 \\
\hline DELTA & .017 & .020 & .149 & .820 & .415 \\
\hline ETA & -.055 & .022 & -.663 & -2.506 & .015 \\
\hline
\end{tabular}

Legend: IT1 - The efficiency of perceptual processors; AL4 - The efficiency of serial processors; S1 - The efficiency of parallel processors; EPSILON - Activity regulation; HI - Regulation of organic functions; ALFA - Regulation of defense reactions;

SIGMA - Regulation of attack reactions; DELTA - Coordination of regulatory functions; ETA - Integration of regulatory functions; B - Beta coefficient; SD - Standard deviation; $\boldsymbol{t}$ - Student's t distribution; $\boldsymbol{p}$ - Probability.

statistically significant effect was achieved with variables: visual test of specializing (S1) designed for the assessment of simultaneous education of spatial relations in which the process of establishing and restructuring independent from the quantity previously acquired information, test anxiety (alpha) that was used to estimate the efficiency of the system for the regulation and control of defense reactions and test social disintegratedness (ETA) that was used to estimate the efficiency of the integration of regulatory functions, whose function is to integrate conative regulatory process under the aspect of the structure of social fields.

\section{DISCUSSION}

The structure of applied anthropological characteristics in this study is entirely consistent with the purposes of identification and development of skills , attributes and students' knowledge which are impor- tant for the methodological design of teaching process especially in the application acquired knowledge in the observed motoric problems. The results of this study showed a significant effect of associated variables for assessing cognitive and conative characteristics on the performance of the defense against attacks by the hand to the head, whereby a single statistically significant effect in explaining the criterion has been achieved : visual test of specializing (S1) designed for simultaneous assessment of education of spatial relations, test of anxiety (alpha) that was used to estimate the efficiency of the system for the regulation and control of defense reactions and test social disinterestedness (ETA) that was used to estimate the efficiency of the integration of regulatory functions, based on which we can assume that these variables are predictive for the successful execution of the defense against attacks by the hand to the head from special physical education program and should therefore be taken into consideration in the planning and 
realization of the processes in solving situational-motor problems in familiar and unfamiliar conditions. Explanation of the obtained results should be primarily looked for in a well-developed abilities to search the visual field and locate objects in it, low intensity mechanism for the regulation and control of defense reactions which requires good control of anxiety, probably because the subjects in the course of training of the given motor problem knew in advance in what way will their partner perform the motor movement and have in that way gained the confidence and trust of each other, whereby in the implementation of techniques of attack and defense, there was no fear of injury because of the subjects' guarded »each other. It should be pointed that in the execution of punches to the head a significant deviation from the real attack was noticed and that the subjects while solving problem situations were very confident because they have handled the situation in familiar terms, during which they have applied adopted solutions, whereby they prefer »safer« techniques that carry less risk in their implementation, which made the implementation of motor programs during execution techniques of defense and counter-attack easier. Considering the fact that it is a punch in the head, cognitive involvement in the execution of the defense could be explained by the fact that in such situations a man reflexively (we could say, without consciousness, if that's possible) protects, and it is not to expect a significant cognitive process before and during the performance of defense techniques, but it would rather be talked about the ability to control emotions (that is, above all, the fear and excitement). Furthermore, the reason for these results can be found in the structure of the performance of the punches. The punch is characterized by terminal movement that has a beginning and an end and which is performed by an initial impulse of force, as an initial ballistic phase, followed by a phase reaction based on the current speed and position. The first part of the movement is performed by controlling the initial impulse whereby its subsequent sequence considering to high speed performance cannot be corrected. The support of this claim comes from the fact that the hand hit are genetically encoded natural movements and therefore do not require significant cognitive charge, such as defense, which in our case is characterized more by reflex than a learned movement, which is completely understandable given the relatively small number of lessons and repetition. To have a complete picture about the relationship between psychological characteristics and efficiency of the performance of the defense against attacks by the hand to the head is necessary to consider a study on the featured characteristics which are conducted on a similar sample subjects. Mudrić and Jovanović (2001) on a sample of 102 students of the fifth semester of the Police College in Zemun conducted a research of cognitive and conative characteristics with had the aim of forming a model of the psychological characteristics of students of the Police College. The obtained results speak about psychological profile of students who expressed a high factor of crystallized intelligence, conscientiousness, dependability, responsibility, emotional stability, perseverance, self-confidence and serenity. If we compare the results above mentioned research with the results of our study, it is obvious that the obtained results very similar. The explanation can be found in the fact that both subjects in the competition for admission to school were subjected to nearly the same or similar tests for the assessment of psychological characteristics, as well as that during the education they studied identical teaching contents, which are implemented in the same or similar conditions. Kasum and Bačanac (2007) investigated the association between individual psychological characteristics of elite wrestlers and their main scoring techniques, during which they found that the choice of the dominant techniques in wrestling was associated with a specific psychological characteristics of wrestlers. It was found that the wrestlers that are characterized by a higher level of sport competition anxiety choose and use scoring techniques which bear higher risk and uncertainty lead to lower his score. This is in agreement with the results of research conducted by Popović (1990) which established that the performance of dedicated techniques in judo, have a great participation of conative characteristics that are defined by anxiety and obsessive tendencies. However, the results of this research when it comes to the level of anxiety, differ from the results of these studies, which is understandable given the fact that our subjects defense is performed in known conditions, while the wrestlers and judoists were doing sports fight in order to achieve competitive results, and expected much fear in terms of achieving competitive success. So, if we take into consider the fact that the subject of this study were students of the Internal Affairs College, who are in the process of learning the defense from an attack by hand an activity performed several times in familiar terms, it is reasonable to assume that they have gained trust and confidence to for the performance of the defense, and is understandable that they did not show fear of injury or the loss of points, as a possible cause of anxiety behavior. 
Blazevic and Malacko (2007) conducted a research to determine the effects of cognitive abilities on individual specific motor skills by top boxers. By applying a regression analysis of they obtained results under which the test AL - 4 had a statistically significant impact on all criterion variables, and test IT - 1 had an impact on the execution speed of the combined blows on the bag, performances of hops with both legs for 10 seconds, performance of left and right uppercuts and performing a series of 100 combined shots at the coaches hand. When comparing their results with the results of this study it will be seen that they are very different. Namely, the authors have investigated the combination of successive techniques by default form, while in this study, subjects had to simultaneously process the incoming information and is quite understandable that a significant role in the defense against attacks by the hand to the head has the capability of simultaneous assessment of education of spatial relations in which the process of establishing and restructuring independent of the amount of previously acquired information. From the aforementioned reasons it is obvious that the psychological characteristics with other features and capabilities are a very important determinant which can decide on the ultimate success in the integrated education students of the Internal Affairs College in solving situational-motor problems of different levels of complexity in the known and unknown conditions.

\section{CONCLUSION}

Bearing in mind that besides the techniques, tactics and physical training, psychological regulatory mechanisms are very important for the ultimate success, based on the fact that different individuals vary in their characteristics, there is a need for the special physical education to be a function of individual capabilities and characteristics of students. For this reason, research was conducted on the students of the third year of the Internal Affairs College in Banja Luka, which was aimed to determine whether and to what extent the observed psychological characteristics of students of the Internal Affairs College in Banja Luka have an impact on the efficiency of the defense against attacks by the hand to the head. The obtained results of the regression analyzes revealed also that psychological characteristics have a statistically significant impact on the efficiency of the performance of the defense against attacks by the hand to the head, where it is possible to conclude that the subjects who had developed a better ability to search the visual field and locating objects in it and good control of anxiety were more effective in the performance of the defense against attacks by the hand to the head. Thus, the results of this research would from the aspect of methodology training provide a choice of new teaching methods and resources, introducing to the program structure of subject matter SPE, certain problem situations that would address the harmonization of possible solutions to the psychological characteristics and capabilities of each individual.

\section{REFERENCES}

Blažević, S., \& Malacko, J. (2007). Evaluacija doprinosa kognitivnog statusa boksača uspjehu u izvođenju specifičnih motoričkih struktura [Evaluation of the contribution of cognitive boxer success in the execution of specific motor structure]. Acta Kinesiologica, 1(2), 12-17.

Kasum, G., \& Bačanac, Lj. (2007). Povezanost pojedinih psiholoških karakteristika vrhunskih rvača i njihovih glavnih poentirajućih tehnika [Connection between some psychological characteristics of elite wrestlers and their main scoring techniques]. Fizickea kultura, 61(1-2), $1-12$.

Milošević, M., Mudrić, R., Jovanović, S., Amanović, Đ., \& Dopsaj, M. (2005). Konstituisanje sistema za upravljanje trenutnim $i$ kumulativnim edukativnim $i$ trena:̌nim efektima (upravljanje u SFO)

[Constituting system for managing current and cumulative educational and physical training effects (management SFO)]. Beograd, RS: Monografija iz istraživačkog projekta.

Momirović, K., \& Horga, S. (1990). Povezanost rezultata u testovima intelektualnih sposobnosti i osobina ličnosti [Correlation of results of tests of intellectual abilities and personality factors]. Primijenjena psibologija, 11(1), 31-36.

Momirović, K., Wolf, B., \& Džamonja, Z. (1992). Kiberneticka baterija konativnib testova [Cybernetic battery of cognitive tests]. Beograd, RS: Savez društva psihologa Srbije, Centar za primijenjenu psihologiju.

Mudrić, R., \& Jovanović, S. (2001). Model psiholoških karakteristika studenata VŠUP [Model psychological characteristics of students of College of Interior]. Treći z̧bornik radova nastavnika Više škole unutrašnjïh poslova (pp. 6380). Beograd, RS: Viša škola unutrašnjih poslova.

Popović, D. (1990). Struktura kognitivnih sposobnosti judista [The structure of cognitive 
abilities of judokes]. Scientific Congress, Valorisation of Program's Effects in Physical Culture. Novi Sad, RS: Fakultet fizičke kulture.

Stoiljković, S. (1995). Odnosi između inteligencije i ličnosti [Relationship between intelligence and personality]. Psibologija, 1-2, 29-43.

Vučinić, B., Popović, B. V., \& Momirović, K. (1992). Prilog poznavanju odnosa između intelektualnih sposobnosti i osobina ličnosti [Contribution to the knowledge of the relationship between intellectual abilities and personality factors]. Zbornik instituta za kriminološka i sociološka istraživanja, 21(1-2), 178200.

Wolf, B., Momirović, K., \& Džamonja, Z. (1992). Baterija testova inteligencije [Battery of intelligence tests]. Beograd, RS: Savez društva psihologa Srbije, Centar za primijenjenu psihologiju.

Received: October 10, 2013

Revision received: December 2, 2013

Accepted: December 23, 2013

Correspondence to:

Darko Paspali, PhD

Visoka škola Unutrašnjih poslova

Buluvera V. Živojina Mišića 10A

78000 Banja Luka

Bosnia and Herzegovina Phone: 0038766240357

E-mail:dpaspalj@yahoo.com 